\title{
Thyroid Metastases from Clear Cell Renal Carcinoma: Presentation of an Unusual Case and Literature Review
}

\author{
Rafael Cholvi Calduch ${ }^{1}$, Raquel Alfonso-Ballester ${ }^{1}$, Clara Alfaro-Cervelló ${ }^{2}$, \\ Norberto Cassinello Fernández ${ }^{1}$, Joaquín Ortega Serrano ${ }^{1}$ \\ ${ }^{1}$ Departments of Surgery, Clinic University Hospital of Valencia, Valencia, Spain \\ ${ }^{2}$ Departments of Pathology, Clinic University Hospital of Valencia, Valencia, Spain \\ Email: raquelalfonsoballester@msn.com
}

How to cite this paper: Calduch, R.C., Alfonso-Ballester, R., Alfaro-Cervelló, C., Fernández, N.C. and Serrano, J.O. (2017) Thyroid Metastases from Clear Cell Renal Carcinoma: Presentation of an Unusual Case and Literature Review. Journal of Cancer Therapy, 8, 941-947.

https://doi.org/10.4236/jct.2017.811083

Received: October 12, 2017

Accepted: November 13, 2017

Published: November 16, 2017

Copyright (c) 2017 by authors and Scientific Research Publishing Inc. This work is licensed under the Creative Commons Attribution International License (CC BY 4.0).

http://creativecommons.org/licenses/by/4.0/

\begin{abstract}
Clear cell type renal cell carcinoma is a malignant tumor that can metastasize to many locations, but unusually spreads to thyroid. Therefore it is important to know the oncological background of the patient and to perform a complete immunohistochemical analysis of the thyroid lesion to obtain a correct diagnosis. Thyroidectomy can be considered in patients with no other metastasis or in those who present compressive symptoms as a palliative measure. We expose the case of a patient with clear cell type renal cell carcinoma, with a previously known bone metastasis of renal origin and symptomatic goiter containing a nodule that was found to be a metastasic lesion.
\end{abstract}

\section{Keywords}

Clear Cell Type Renal Cell Carcinoma, Thyroid Metastasis, Immunohistochemistry, Thyroidectomy

\section{Introduction}

Renal cell carcinomas (RCCs) cause for 80 to 85 percent of all primary renal neoplasm. Its incidence varies from region to region. In Europe, we diagnose 84,000 new cases each year and RCCs cause aproximately 35,000 deaths [1]. This type of lesion is 50 percent more common in men than woman [2] and occurs predominantly in the sixth to eight decade [3]. Risk factors associated with a increased incidence of RCC include smoking, hypertension, obesity, acquired cystic disease of the kidney, occupational exposure to cadmium or asbesto, and others [4]. Several subtypes of this type of neoplasm have been identified but the 
most common histologic pattern is clear cell which supposes 75 to 85 percent of RCC [5].

Sporadic clear cell carcinomas have a deletion of chromosome $3 \mathrm{p}$ in more than 90 percent of cases [6] and they arise from the proximal tube [7]. Moreover this type of RCC is specifically associated with von Hippel-Lindau disease [8]. Both variants are histologically indistinguisable. Patients with higher nuclear grade or sarcomatoid pattern have a poor prognosis [9].

Clear cell renal carcinoma (CCRC) is a tumor with great metastatic capacity, although the presence of metastases in the thyroid gland is very uncommon. There is little evidence in the literature about it and its diagnosis is often complex [10]. We expose the case of a patient with clear cell type renal cell carcinoma, thyroid metastasis with a previously known bone metastasis of renal origin and large goiter with compressive symptoms.

\section{Case Report}

We present the case of a 65-year-old caucasian male, with personal history of Obesity (BMI $=38$ ), Diabetes Mellitus, High blood pressure and Hipercholesterolemia, Diagnosed of non-symptomatic goiter more than 10 years ago.

In 2011 he underwent a laparoscopic rectum resection due to colorectal adenocarcinoma (pT3, N0, M0). In August 2015 a right renal tumor and a sternal lithic lesion were found in control CT without signs of rectal relapse. Sternal biopsy was compatible with metastases from clear cell renal carcinoma (Figure 1).

In September 2015 the patient underwent total right laparoscopic nephrectomy and pathological anatomy offered the diagnosis of CCRC pT3 N0 M1. Posterior Nuclear Medicine Bone scan showed no other methastasis.

In February 2016, the patient was sent to our endocrine surgery consult to evaluate a goiter growth in the last year, with compressive symptoms and thyroid hyperfunction. Physical examination noticed a giant goiter about $10-15 \mathrm{~cm}$, in the right cervical area. Thyroid ultrasound showed an enlarged gland, mainly

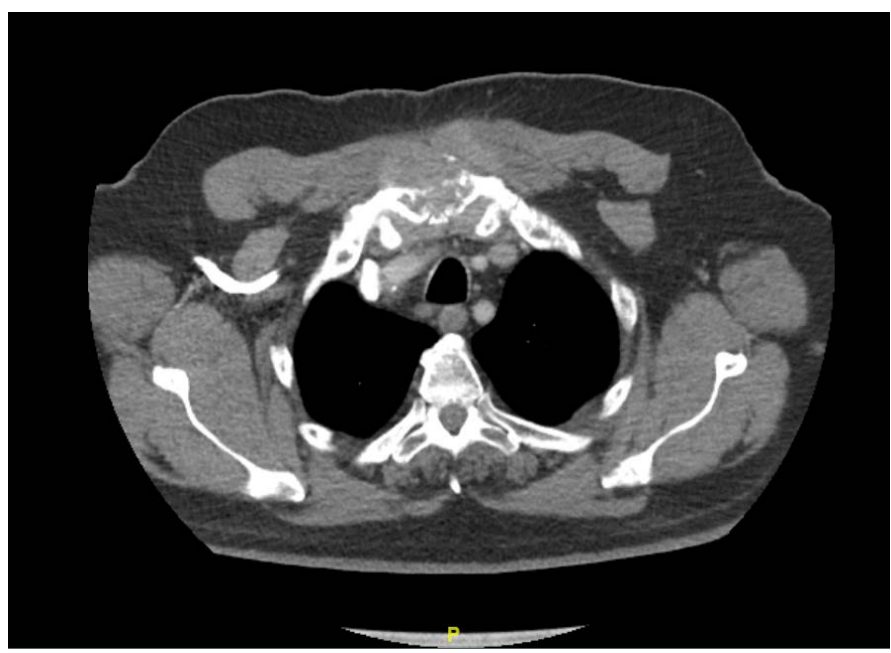

Figure 1. CT scan demonstrating the sternal lithic lesion. 
in the right lobe. It presented heterogeneous echogenicity, with cystic areas and nodular images. CT scan images were also obtained to evaluate size and relation with other structures (Figure 2).

Fine needle biopsy showed colloid material, with no malignancy findings. After assessing clinic, size increase and the oncologic background, the patient underwent a total thyroidectomy in May 2016. Intraoperatively, a large cervical tumor was observed with greater size of the right lobe, measuring approximately $12 \times 10 \mathrm{~cm}$ and moving the trachea to the left.

The anatomopathological analysis of the surgical specimen described micrometastasis by clear cell renal carcinoma. The immunohistochemical study was negative for Thyroid Transcription Factor 1 (TTF-1), although it was not valued for vimentin, cytokeratin 8 and CD10 because of the small size of the lesion that did not allow an adequate study (Figure 3).

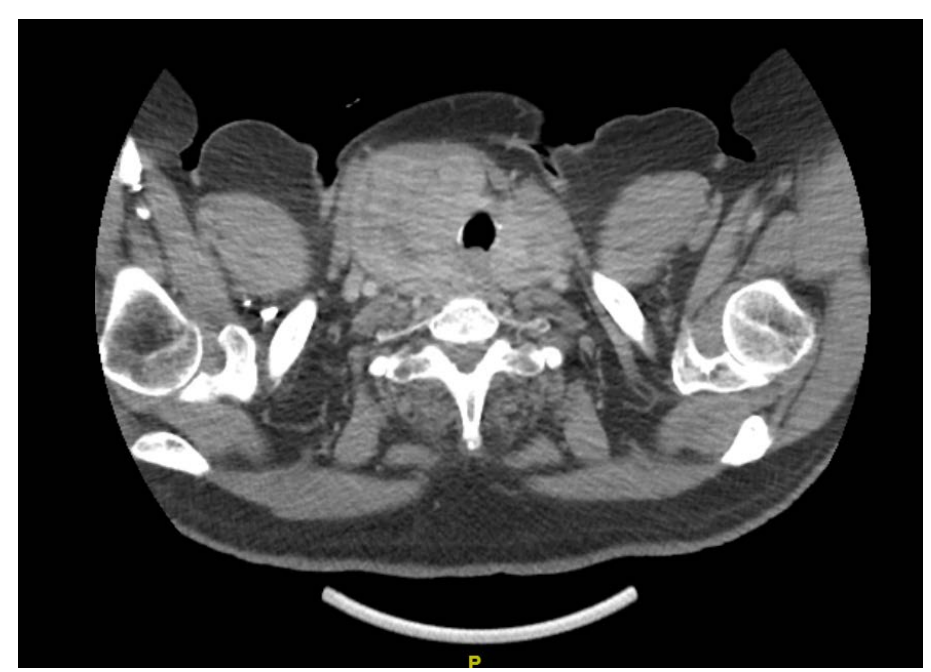

(A)

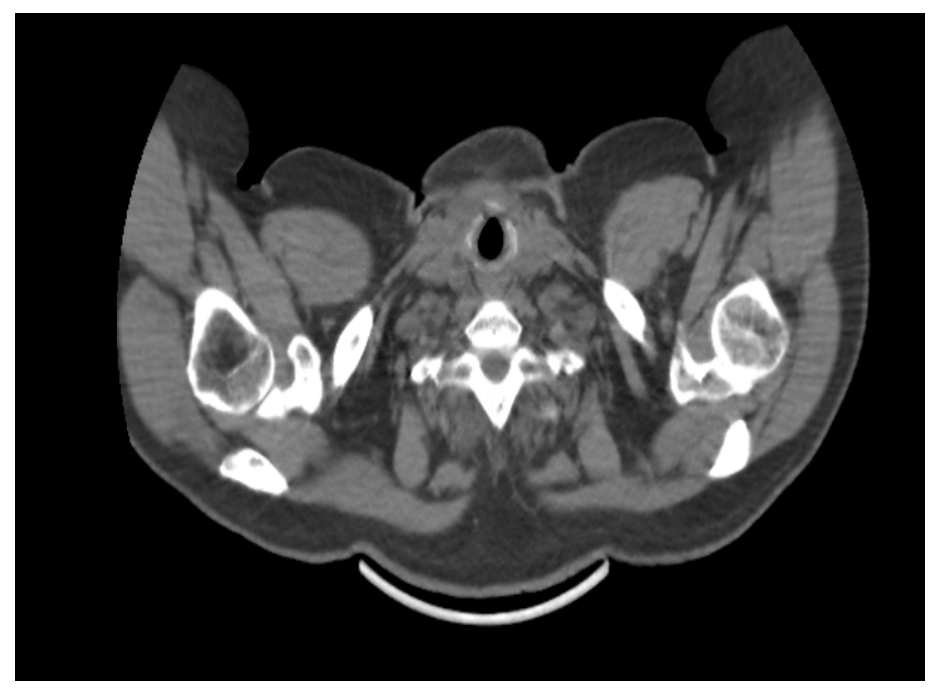

(B)

Figure 2. CT scan showing the large goiter of the patient. (A) Prior to surgery; (B) After thyroidectomy. 

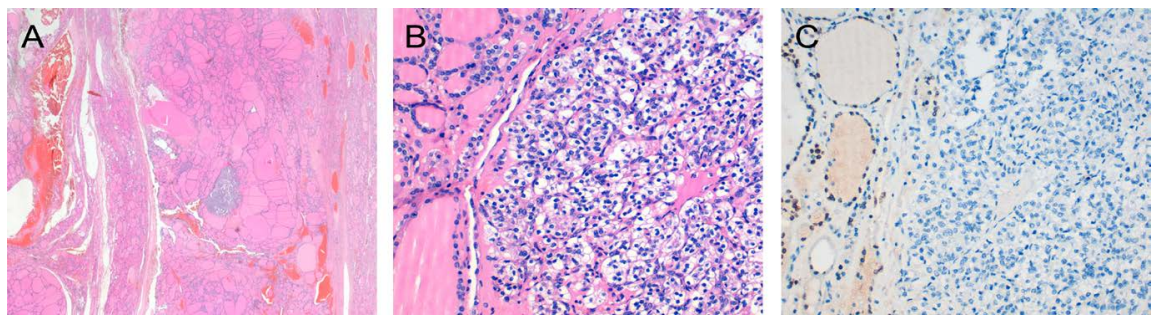

Figure 3. Histopathology of thyroid micrometastasis from clear cell renal carcinoma. (A) Panoramic view of thyroid tissue showing nodular hyperplasia and a clear cell area (hematoxylin-eosin, $3 \times$ ); (B) Clear broad cytoplasm cells and small irregularly shaped nuclei are identified, which form acini separated by fine vascular axes (hematoxylin-eosin, 200x); (C) The immunohistochemical study of TTF-1 is negative in the metastatic cells and positive in the thyroid parenchyma $(200 \times)$.

The patient had no postoperative complications. He is currently under follow-up and treated with Sunitinib $50 \mathrm{mg}$ per day for 4 weeks every 6 weeks and radiotherapy of the sternal lesion. After 2 years there is no evidence of disease progression.

\section{Discussion}

Clear cell renal tumor accounts for $3 \%$ of adult malignancies. It is characterized by an intense vascularization, an unpredictable clinical behavior and high metastatic capacity with a predilection for lung, liver, bone and adrenal gland. However, dissemination to the thyroid gland is rare, accounting for $1 \%-4 \%$ of malignant thyroid disease [10] [11] [12] [13]. For authors such as Chen and Porcell, CCRC is the most commonly metastatic tumor in the thyroid, accounting for $50 \%$ of cases. Other primary tumors that frequently metastasize to the thyroid gland are breast, lung, and lymphoid tissue [14] [15].

The thyroid metastases may appear synchronous with the primary tumor or years after treatment [10] [12]. Its presentation as palpable thyroid nodule is unusual and it is more frequent an increase of diffuse and non-painful glandular size. Thyroid function is usually normal, although hyperfunctioning goiter was detected in our case, which occurs in $20 \%$ of cases [10] [13]. Radiological studies can guide diagnosis but the role of pathological anatomy is essential. In our case the ultrasonography did not give much information apart from an heterogenicity that may involve a malignant lesion. This patient had been under surveillance of his goiter for more $\tan 10$ years. Although it was a huge goiter it never gave symptoms, so no surgery was required. It was not until the goiter began to grow and give symptoms that the patient was referred to surgery. Probably the oncological background should have been taken into account and the patient should have been referred to us earlier.

Fine needle biopsy can be diagnostic in many cases [16]. It was not useful in ours, probably due to the small size of the lesion. The typical histology of thyroid micrometastasis from CCRC shows nodular hyperplasia and a clear cell area, with clear cytoplasmic cells and small nucleus of irregular size [17]. However, 
the best laboratory tool available for a correct defferential diagnosis is immunohistochemistry. CCRC is positive for Cytokeratin 8, 18 and 19, Epithelial Cell Membrane Antigen (EMA), Vimentin (variably), Renal Cell Carcinoma Antigen and CD10. In contrast, it is negative for TTF-1 [18] [19], which is a protein that is expressed in $90 \%-100 \%$ of cases in lesions of thyroid origin. In our case the sample was insufficient to evaluate the proteins expressed by CCRC, although the history of the patient, the presence of CCRC bone metastases and the thyroid lesion which was negative for TTF-1 helped to guide the diagnosis.

The published series have few cases and the most extensive one is Hegerova serie [20] in the Mayo Clinic, with 97 cases of thyroid metastases. The limited literature on this subject describes a good prognosis in patients undergoing thyroidectomy when they do not associate other metastases. However, patients with disseminated disease have a poor prognosis, and thyroidectomy is performed as a palliative measure when exist compressive symptoms [10] [21] [22]. In our case the diagnosis was reached after the surgery, which was indicated by the patient's clinic and the size of the lesion, but in cases with no symptoms (and when there is no evidence of other metastasis) a newly appeared suspitious thyroid lesion should be considered for a total thyroidectomy in order to achieve a complete control of the oncological disease.

\section{Conclusion}

Thyroid metastases from CCRC are extremely uncommon, so there is little evidence in the literature about its diagnosis and therapeutic management. It is essential to know the oncologic history of the patient and to perform a complete immunohistochemical analysis of the lesion for establishing a correct diagnosis. In patients with a primary tumor removed and no signs of disseminated disease, we must not forget this entity, because its diagnosis and excision can improve survival.

\section{References}

[1] Ferlay, J., Steliarova-Foucher, E., Lortet-tieulent, J., et al. (2013) Cancer Incidence and Mortality Patterns in Europe: Estimates for 40 Countries in 2012. European Journal of Cancer, 49, 1374. https://doi.org/10.1016/j.ejca.2012.12.027

[2] Siegel, R., Ward, E., Brawley, O. and Jemal, A. (2011) Cancer Statistics, 2011. The Impact of Eliminating Socioeconomic and Racial Disparities on Premature Cancer Deaths. CA: A Cancer Journal for Clinicians, 61, 212.

https://doi.org/10.3322/caac.20121

[3] Siegel, R.L., Miller, K.D. and Jemal, A. (2017) Cancer Statistics, 2017. CA: A Cancer Journal for Clinicians, 67, 7. https://doi.org/10.3322/caac.21387

[4] Flaherty, K.T., Fuchs, C.S., Colditz, G.A., et al. (2005) A Prospective Study of Body Mass Index, Hypertension and Smoking and the Risk of Renal Cell Carcinoma (United States). Cancer Causes Control, 16, 1099. https://doi.org/10.1007/s10552-005-0349-8

[5] Torkel, S. and Van der Berg, E. (1995) Morphological Classification of Renal Cancer. World Journal of Urology, 13, 153. https://doi.org/10.1007/BF00184870 
[6] Anglard, P., Troy, K., Brauch, H., et al. (1991) Molecular Analysis of Genetic Changes in the Origin and Development of Renal Cell Carcinoma. Cancer Research, 51, 1071-1077.

[7] Presti Jr., J.C., Rao, P.H., Chen, Q., et al. (1991) Histopathological, Cytogenetic, and Molecular Characterization of Renal Cortical Tumors. Cancer Research, 51, 1544.

[8] Beroukhim, R., Brunet, J.P., Di Napoli, A., et al. (2009) Patterns of Gene Expression and Copy Number Alterations in Von-Hippellindau Disease Associated and Sporadic Clear Cell Carcinoma of the Kidney. Cancer Research, 69, 4674. https://doi.org/10.1158/0008-5472.CAN-09-0146

[9] Oda, H. and Machinami, R. (1993) Sarcomatoid Renal Cell Carcinoma. A Study of Its Proliferative Activity. Cancer, 71, 2292. https://doi.org/10.1002/1097-0142(19930401)71:7<2292::AID-CNCR2820710720>3. $\underline{0 . \mathrm{CO} ; 2-3}$

[10] Duggal, N.M. and Horattas, M. (2008) Metastatic Renal Cell Carcinoma to the Thyroid Gland. Endocrine Practice, 14, 1040-1046. https://doi.org/10.4158/EP.14.8.1040

[11] Arroyo, C., Palacios, P., Uribe, N., Barrera, M. and Feria, G. (2005) Metástasispocofrecuentes del carcinoma renal. [Uncommon Metastases in Renal Carcinoma.] Gaceta Médica de México, 14, 543-546.

[12] Iesalnieks, I., Winter, H., Bareck, E., Sotiropoulos, G.C., Goretzki, P.E., Klinkhammer-Schalke, M., et al. (2008) Thyroid Metastases of Renal Cell Carcinoma: Clinical Course in 45 Patients Undergoing Surgery. Assessment of Factors Affecting Patients' Survival. Thyroid, 18, 615-624. https://doi.org/10.1089/thy.2007.0343

[13] De Stefano, R., Carluccio, R., Zanni, E., Marchiori, D., Cicchetti, G., Bertaccini, A., et al. (2009) Management of Thyroid Nodules as Secondary Involvement of Renal Cell Carcinoma: Case Report and Literature Review. Anticancer Research, 29, 473-476.

[14] Chen, H., Nicol, T.L. and Udelsman, R. (1999) Clinically Significant, Isolated Metastasis Disease to the Thyroid Gland. World Journal of Surgery, 23, 177-181. https://doi.org/10.1007/PL00013162

[15] Porcell, A.I., Hitchcock, C.L. and Keyhani-Rofagha, S. (2000) Use of Inmunohistochemistry in Fine Needle Aspiration in Patients with a History of Malignancy. Acta Cytologica, 44, 393-398. https://doi.org/10.1159/000328485

[16] Kim, T.Y., Kim, W.B., Gong, G., Hong, S.J. and Shong, Y.K. (2005) Metastasis to the Thyroid Diagnosed by Fine-Needle Aspiration Biopsy. Clinical Endocrinology ( $\mathrm{OX}^{-}$ ford), 62, 236-241. https://doi.org/10.1111/j.1365-2265.2005.02206.x

[17] Lasser, A., Rothman, J. and Calamia, V. (1985) Renal-Cell Carcinoma Metastatic to the Thyroid. Aspiration Cytology and Histologic Findings. Acta Cytologica, 29, 856-858.

[18] Hefess, C.S., Wenig, B.M. and Thompson, L.D. (2002) Metastatic Renal Cell Carcinoma to the Thyroid Gland. A Clinico-Pathologic Study of 36 Cases. Cancer, 95, 1869-1878. https://doi.org/10.1002/cncr.10901

[19] Murphy, W.M., Grignon, D.J. and Perlman, E.J. (2004) Tumors of the Kidney, Bladder and Related Urinary Structures 2004 (AFIP Atlas of Tumor Pathology 4th Series). American Registry of Pathology, Rockville.

[20] Hegerova, L., Griebeler, M.L., Reynolds, J.P., Henry, M.R. and Gharib, H. (2015) Metastasis to the Thyroid Gland: Report of a Large Series from the Mayo Clinic. American Journal of Clinical Oncology, 38, 338-342. https://doi.org/10.1097/COC.0b013e31829d1d09 
[21] Calò, P.G., Pisano, G., Medas, F., Tatti, A., Pittau, M.R., et al. (2013) Intraoperative Recurrent Laryngeal Nerve Monitoring in Thyroid Surgery: Is It Really Useful? Clinical Therapeutics, 164, 193-198.

[22] Calò, P.G., Tatti, A., Medas, F., Petruzzo, P., Pisano, G., et al. (2012) Forgotten Goiter. Our Experience and a Review of the Literature. Annali Italiani di Chirurgia, 83, 487-490. 